\title{
Використання засобів функціонального тренінгу у підвищенні показників фізичного стану юнаків
}

\author{
Олександр Петрачков ${ }^{1}$, Олена Ярмак²
}

${ }^{1}$ Національний університет оборони України імені Івана Черняховського, Київ, Україна

2 Білоцерківський національний аграрний університет, Біла Церква, Україна

Анотація. Однією із актуальних проблем у практиці фрізичного виховання студентської молоді на сьогодні стоїть питання пошуку та розробки оздоровчих технологій, які будуть сприяти збереженню та зміцненню фізичного здоров'я. Мета. Визначити вплив засобів функціонального тренінгу на фрізичний стан юнаків 18-19 років у процесі фізичного виховання. Методи. Аналіз літературних джерел і узагальнення даних спеціальної науковометодичної літератури; педагогічне спостереження, педагогічне тестування фізичної підготовленості та педагогічний експеримент; методи антропометрії і фрункціональної діагностики; методи математичної статистики. Результати. В ході педагогічного експерименту було встановлено, що заняття із використанням засобів функціонального тренінгу мали позитивний комплексний вплив на роботу кардіо-респіраторної системи, рівень фізичної працездатності і підготовленості. Порівнюючи результати показників фуункціонального стану наприкінці педагогічного експерименту, виявили у юнаків вірогідні зміни $(p<0,05 ; p<0,01)$ у показниках частоти серцевих скорочень у стані відносного спокою та пробах із затримкою дихання Штанге і Генчі. Середньогрупові значення індексу Рус'є та Робінсона теж зазнали позитивних вірогідних змін $(p<0,05 ; p<0,01)$, що вказує на покращення ффункціональної здатності серцевого м'яза, резервних можливостей серцево-судинної та дихальної систем. Завдяки заняттям функціональним тренінгом переважна більшість юнаків змогли скласти тести і нормативи щорічного оцінювання фрізичної підготовленості населення України на позитивні бали. Отримані результати педагогічного експерименту дають підстави стверджувати, що засоби функціонального тренінгу, які застосовували у процесі фізичного виховання, мали позитивний вплив на переважну більшість досліджуваних показників.

Ключові слова: фізичний розвиток, кардіо-респіраторна система; фізична підготовленість, студентська молодь.

\section{Oleksandr Petrachkov, Olena larmak}

\section{USAGE OF FUNCTIONAL TRAINING MEANS TO INCREASE PHYSICAL STATUS INDICES OF YOUNG BOYS}

Abstract. One of the current problems in the practice of physical education of student youth today is the search for and development of health-related technologies that will help maintain and enhance physical health. Objective. To determine the influence of functional training on the physical condition of young boys aged 18-19 in the process of physical education. Methods. Analysis of literary sources and generalization of data of special scientific and methodical literature; pedagogical observation, pedagogical testing of physical fitness and pedagogical experiment; methods of anthropometry and functional diagnostics; methods of mathematical statistics. Results. During the pedagogical experiment it was found that classes with the use of functional training had a positive complex impact on the cardiorespiratory system, the level of physical work capacity, and fitness. Comparing the results of functional status indices at the end of the pedagogical experiment, probable changes $(p<0.05 ; p<0.01)$ in heart rate at rest and tests with breath holding Stange and Genchi were revealed. The average group values of the Rufier and Robinson index also underwent positive probable changes $(p<0.05 ; p<0.01)$, which indicates an improvement in the functional capacity of the heart muscle, the reserve capacity of the cardiovascular and respiratory systems. Thanks to functional training, the vast majority of young people were able to pass tests and standards for the annual assessment of physical fitness of the population of Ukraine with positive scores. The obtained results of the pedagogical experiment give grounds to claim that the means of functional training, which were used in the process of physical education, had a positive effect on the vast majority of the studied indices. Keywords: physical development, cardiorespiratory system; physical fitness, student youth

Petrachkov 0., larmak 0. Usage of functional training means to increase physical status indices of young boys. Theory and Methods of Physical education and sports. 2021; 1 : 50-54

DOI: 10.32652/tmfvs.2021.1.50-54
Петрачков 0, Ярмак 0. Використання засобів функціонального тренінгу у підвищенні показників фізичного стану юнаків. Теорія і методика фрізичного виховання і спорту. 2021; 1: 50-54 DOI: 10.32652/tmfvs.2021.1.50-54
Вступ. Одним із важливих пріоритетних завдань сучасної системи фрізичного виховання у закладах вищої освіти є розробка підходів, спрямованих на збереження та зміцнення фрізичного здоров'я студентської молоді [1-6]. Як вказують ряд авторів [10, $11,13,15]$, за останні роки спостерігаються негативні тенденції у медикодемографрічних показниках здоров'я молодих осіб. Найбільше занепокоєння викликає зменшення кількості абсолютно здорових молодих людей та значне зростання хронічних захворювань як у юнаків, так і у дівчат. Одними 3 негативних факторів, які впливають на стан здоров'я студентської молоді, учені $[10,11,13,15]$ вважають наявність постійних розумових та психоемоційних навантажень, підвищені вимоги до обсягу і якості знань, інформаційні стреси, малорухомий спосіб життя, порушення режиму харчування, праці та відпочинку. На фоні явного десріциту фрізичних навантажень у переважної більшості юнаків і дівчат спостерігається виражене напруження регуляторних механізмів та зниження функціональних можливостей організму [15].

За таких умов стає актуальним впровадження в освітній процес інноваційних оздоровчих технологій, які будуть зорієнтовані на підвищення рівня фрізичного стану. До таких технологій слід віднести функціональний тренінг, який прийнято розглядати як один із видів занять, що базується на природних рухах людини і спрямований на розвиток основних фрізичних якостей та вдосконалення рухових здібностей, корекцію статури, а також вдосконалення основних життєво важливих систем організму [7, 12, 14].

На сьогодні в системі фрізичного виховання студентської молоді функціональний тренінг стає все більш популярним та затребуваним. До головних його переваг, порівняно з традиційними засобами фрізичного виховання, на думку Д. І. Цись, Н. О. Цись 
[12], належить велика варіативність різних вправ, які переважно виконуються 3 обтяженням власного тіла і не потребують спеціально обладнаних приміщень. Н. О. Базилевич, О. С. Тонконог [4] надають перевагу засобам функціонального тренінгу за популярність і затребуваність його серед студентської молоді, а також можливість виконання вправ в умовах дефіциту часу та обмеженого простору. На думку D. A. Kokorev зі співавт. [14], регулярні заняття функціональним тренінгом сприяють розвитку основних рухових якостей, вдосконалюють рухові здібності, прискорюють метаболічні процеси в організмі, а найголовніше підвищують адаптаційні перебудови функціональних систем організму. На високу ефективність засобів функціонального тренінгу під час фрізичної реабілітації осіб з вертеброгенною патологією вказують В. Кормільцев та 0. Лазарєва [7].

Враховуючи сказане, можна констатувати, що система занять функціональним тренінгом актуальна і може бути впроваджена як фрізичне навантаження з оздоровчою спрямованістю в процесі фізичного виховання студентської молоді.

Мета дослідження - визначити вплив засобів фуннціонального тренінгу на фізичний стан юнаків 18-19 років у процесі фрізичного виховання.

Методи й організація дослідження. У дослідженні застосовано комплекс взаємопов'язаних методів: теоретичний аналіз науково-методичної літератури, антропометричні, фрізіологічні, педагогічні, методи математичної статистики. Аналіз і узагальнення науково-методичної літератури здійснювали з метою пошуку матеріалу, що стосується сучасних підходів використання засобів функціонального тренінгу в процесі фрізичного виховання студентської молоді. Антропометричні вимірювання проводили 3 дотриманням таких вимог: масу тіла (МT) визначали у кілограмах з точністю до 0,01 кг; довжину тіла (ДТ) - у сантиметрах з точністю до 1 мм. Отримані показники фрізичного розвитку було використано для розрахунку індексу маси тіла (IMT). Для визначення функціонального стану серцево- судинної системи досліджували частоту серцевих скорочень (ЧСС) у стані відносного спокою, пальпаторно за кількістю ударів за 1 хв. Артеріальний тиск систолічний (АТсист ) та артеріальний тиск діастолічний (АТдіаст) вимірювали у стані відносного спокою за допомогою механічного тонометра «Omron - М-1» (Японія) за методикою Короткова. Для визначення функціонального стану дихальної системи використовували проби із затримкою дихання Генчі і Штанге. Для вивчення стану киснево-транспортної системи, а саме аеробних можливостей, визначали індекс Робінсона.

Рівень фрізичної працездатності визначали за допомогою індексу Русфє. Для визначення фрізичної підготовленості використовували рухові тести і нормативи щорічного оцінювання фрізичної підготовленості населення України. Для оцінювання рівноваги використовували ускладнену пробу Ромберга з заплющеними очима. Під час тестування звертали увагу на ступінь стійкості пози, тривалість збереження рівноваги. Силові якості визначали за результатами кистьової динамометрії правої та лівої руки у кілограмах, за допомогою динамометра, у вихідному положенні стоячи з витягнутою до низу рукою.

Статистичний аналіз даних проводили з використанням комп'ютерного пакета прикладних програм для обробки статистичної інформації Statistica 10.0 (StatSoft,Inc., США). Методи математичної статистики застосовували для доведення закономірностей, виявлених у процесі дослідження, коректного опрацювання отриманих результатів та для оцінювання впливу занять функціональним тренінгом на фізичний стан юнаків. При середньому обсязі вибірки $(30 \leq n \leq 100)$ перевірили нормальність розподілу кількома методами, застосовуючи критерій Шапіро-Уілка і критерій перевірки коесріцієнтів асиметрії та ексцесу. Для вибірок, які не відповідають закону нормального розподілу, виконували непараметричний дисперсійний аналіз Краскела-Уолліса. Було використано статистичний аналіз, який передбачав обчислення середнього арифметичного, середнього квадратично- го відхилення та коесріцієнта варіації. Достовірність для всіх досліджень було встановлено на рівні не нижче $p \leq 0,05$.

Наукове дослідження проводили на базі Білоцерківського національного аграрного університету. В досліджені взяли участь 42 юнаки 18-19 років, які навчаються на агробіотехнологічному факультеті та виявили особисте бажання відвідувати заняття 3 функціонального тренінгу. Юнаки раніше не займалися спортом, усі вони студенти першого курсу денної форми навчання, за станом здоров'я віднесені до основної медичної групи.

Під час проведення наукового дослідження в межах існуючих Міжнародних конвенцій та законодавства України було дотримано принципів біоетики в педагогічних дослідженнях та узгоджені всі правові питання. Юнаки були задіяні у педагогічному експерименті добровільно за письмової згоди на оприлюднення їхніх особистих даних під час розгляду та висвітлення результатів дослідження. Наукову роботу виконано відповідно до вимог Європейської конвенції, Статуту Української асоціації з біоетики та нормами GLP (1992р.), відповідно до вимог та норм ICH GCP (2002 р.) і типового Положення з питань етики М03 України № 281 від 01.11.2008 р. та розглянуто на комісії з біоетики Білоцерківського національного аграрного університету.

Результати дослідження та їх обговорення. Методичні особливості побудови навчально-тренувальних занять для юнаків 18-19 років з використанням засобів функціонального тренінгу базувались на дотриманні педагогічних принципів. Попередній контроль функціонального стану та фрізичної підготовленості юнаків дав змогу диференціювати інтенсивність, тривалість та обсяг фрізичного навантаження, а також визначити особливості адаптаційних процесів організму. Заняття фоннціональним тренінгом передбачали виконання швидкісно-силових вправ, вправ на координацію рухів, силу та силову витривалість. Силовий сегмент заняття передбачав використання різних рухів з вагою власного тіла, а також із ви- 
користанням різного роду обладнання. У програмі було запропоновано комбіновані вправи різної складності. Кожна вправа складалась із серії взаємодоповнюючих вправ. Кратність занять становила 4 год на тиждень обов'язкових та 2 год фракультативно. До початку занять фрункціональним тренінгом юнаки відпрацювали дихальні цикли під час виконання кожної окремої вправи, оскільки правильне дихання, а саме тривалість і частота вдиху і видиху, є обов'язковою умовою під час виконання фрізичних навантажень.

Результати, які відображають динаміку показників морфоффункціонального стану протягом педагогічного експерименту під впливом занять функціональним тренінгом представлено в таблиці 1.

Головними параметрами, які відображають фрізичний розвиток іспитованих, слід вважати довжину і масу тіла. Показник ДТ вважається основним стійким показником фрізичного розвитку, який залежить передовсім від генетичних факторів, тоді як МТ, навпаки, $€$ найбільш мінливим показником і залежить крім генетичних фракторів від багатьох інших, таких як внутрішні та і зовнішні чинники. Як показали результати попереднього контролю, середньогрупові показники ДТ, МТ та IMT у юнаків знаходяться в межах норми. Детальний аналіз індивідуальних результатів IMT дав змогу виявити 26,2 \% ( $\mathrm{n}=11$ ) юнаків 3 десіцитом маси тіла, їх власні значення знаходились в діапазонах 17,6-19,4 ум. од. Слід також вказати на те, що обстежувана вибірка юнаків на початок педагогічного експерименту характеризувалася низькими середньогруповими показниками дихальних проб.

Частота серцевих скорочень у стані відносного спокою на початок педагогічного експерименту знаходиться за межами фізіологічної норми 72-85 уд $\cdot$ хв$^{-1}$, тоді як $A T_{\text {сист }}$ та $A T_{\text {діаст }}$ потрапляють в межі норми. Якщо розглядати фрізіологічні норми АТ для юнаків, то В003 пропонує такі параметри - 130-110/70-80 мм. рт. ст. Слід вказати на те, що оптимальний рівень АТ є найбільш важливим фактором для нормальної діяльност серцево-судинної системи. Цей показник постійно знаходиться під контролем різних регуляторних механізмів як свідчать результати досліджень [8, 9], у відповідь на будь-яке відхилення АТ від норми виникають численн ресрлекторні реакції, які призводять до змін показників хвилинного об'єму крові та загального перисреричного опору для повернення рівня АТ до його нормального значення.

Під час порівняння результатів морфоффункціонального стану після впровадження програми фрункціонального тренінгу у юнаків було виявлено вірогідні зміни $(p<0,05 ; p<0,01)$ у показниках ЧСС у стані відносного спокою та пробах із затримкою дихання. Систематичні заняття функціональним тренінгом позитивно вплинули на антропометричні показ ники. Наприкінці педагогічного експерименту значно знизився відсоток юнаків, у яких спостерігався десріцит маси тіла, - 11,9 \% (n= 5). Відбулися і природні закономірні зміни в показниках фрізичного розвитку, середньогруповий показник ДТ збільшився на 1,9 cм, а МТ на 2,2 кг.

Заняття фрункціональним тренінгом позитивно вплинули на показники аеробних можливостей та реакцію серцево-судинної системи на динамічне навантаження. Результати дослідження представлено в таблиці 2. Переважна більшість юнаків на етап попереднього контролю мали індиві- дуальні результати індексів Робінсона та Руф'є, які відповідали рівню нижче середнього і свідчили про низькі аеробні та ффункціональні можливості організму. Після педагогічного експерименту індивідуальні результати цих індексів стали відповідати вище середнього та середньому рівням. Отримані результати можуть вказувати на значне покращення компенсаторних фуннкцій, оскільки зниження ЧСС під час фрізичного навантаження свідчить про декомпенсацію функції серцевосудинної системи

Слід вказати на те, що не у всіх юнаків відбулися позитивні зміни у досліджуваних показниках. Однією 3 причин $є$ нерегулярне відвідування занять.

Наступним етапом нашого дослідження був аналіз впливу функціонального тренінгу на фрізичну підготовленість юнаків. Результати представлено в таблиці 3. На сьогодні дослідженням рівня фрізичної підготовленості юнаків приділяється велика увага в усіх цивілізованих країнах, адже результати можуть вказувати на стан здоров'я молодих людей, а також на рівень розвитку окремих рухових якостей.

Однією з особливостей функціонального тренінгу $€$ його варіативність, що значно розширює арсенал засобів, які можна використовувати під час проведення занять. Використовуючи доволі легкі вправи, можна включити в роботу абсолютно всі гру-

Т а б л и ц я 1. Динаміка морфофрункціональних показників юнаків 18-19 років протягом педагогічного експерименту під впливом занять функціональним тренінгом (n=42)

\begin{tabular}{|c|c|c|c|c|c|}
\hline \multirow{2}{*}{ Показники } & \multicolumn{2}{|c|}{ До експерименту } & \multicolumn{2}{|c|}{ Після експерименту } & \multirow{2}{*}{$\mathbf{p}$} \\
\hline & $\bar{x}$ & S & $\overline{\boldsymbol{X}}$ & S & \\
\hline Довжина тіла, см & 177,9 & 5,26 & 179,8 & 4,18 & $p>0,05$ \\
\hline Маса тіла, кг & 64,7 & 10,04 & 66,9 & 7,55 & $p>0,05$ \\
\hline їМТ, ум. од. & 21,2 & 2,56 & 22,4 & 2,38 & $p>0,05$ \\
\hline ЧСС ${ }_{\text {сп }}$, уд $\cdot$ хв..$^{-1}$ & 89,6 & 4,21 & $81,2^{*}$ & 4,08 & $p<0,05$ \\
\hline$A T_{\text {сист }}$, мМ. рт. ст. & 112,1 & 6,11 & 114,8 & 5,26 & $p>0,05$ \\
\hline$A T_{\text {діаст, }}$ MM. рТ. ст. & 72,2 & 6,09 & 72,9 & 5,03 & $p>0,05$ \\
\hline Проба Штанге, с & 40,1 & 6,27 & $51,4^{\star}$ & 3,02 & $p<0,05$ \\
\hline Проба Генчі, с & 20,2 & 3,44 & $28,7^{\star *}$ & 2,17 & $p<0,01$ \\
\hline
\end{tabular}

Примітки. * різниця статистично значуща на рівні $p<0,05$; * різниця статистично значуща на рівні $p<0,01$ 
Т а б л и ц я 2. Динаміка показників аеробних можливостей та фрізичної працездатності юнаків 18-19 років протягом педагогічного експерименту під впливом занять фуннкціональним тренінгом $(\mathrm{n}=42)$

\begin{tabular}{|c|c|c|c|c|}
\hline Градація & Рівень & До експерименту & $\begin{array}{c}\text { Після } \\
\text { експерименту }\end{array}$ & $\mathbf{p}$ \\
\hline \multicolumn{5}{|c|}{ Їндекс Робінсона, ум. од. } \\
\hline$<69$ & високий & 0,0 & 0,0 & $p>0,05$ \\
\hline $70-84$ & вище середнього & 19,0 & $52,3^{*}$ & $p<0,05$ \\
\hline $85-94$ & середній & 23,9 & $38,2^{*}$ & $p<0,05$ \\
\hline $95-110$ & нижче середнього & 57,1 & $9,5^{\star *}$ & $p<0,01$ \\
\hline$>111$ & низький & 0,0 & 0,0 & $p>0,05$ \\
\hline \multicolumn{5}{|c|}{ Їндекс Руф'є, ум. од. } \\
\hline$<3,9$ & високий & 0,0 & 19,0 & $p<0,05$ \\
\hline $4-6,9$ & вище середнього & 16,7 & $42,8^{*}$ & $p<0,05$ \\
\hline $7-9,9$ & середній & 38,2 & $28,7^{*}$ & $p<0,05$ \\
\hline $10-14,9$ & нижче середнього & 45,1 & $9,5^{\star *}$ & $p<0,01$ \\
\hline$>15$ & низький & 0,0 & 0,0 & $p>0,05$ \\
\hline
\end{tabular}

Примітки. * різниця статистично значуща на рівні $\mathrm{p}<0,05$; ** різниця статистично значуща на рівні $p<0,01$

Т а б л и ц я 3. Динаміка показників фрізичної підготовленості юнаків 18-19 років протягом педагогічного експерименту під впливом занять функціональним тренінгом $(n=42)$

\begin{tabular}{|c|c|c|c|c|c|}
\hline \multirow{2}{*}{ Показники } & \multicolumn{2}{|c|}{ До експерименту } & \multicolumn{2}{|c|}{$\begin{array}{c}\text { Після } \\
\text { експерименту }\end{array}$} & \multirow{2}{*}{$\mathbf{p}$} \\
\hline & $x$ & S & $x$ & s & \\
\hline Біг 100 м, C & 14,4 & 0,79 & $13,5^{*}$ & 0,48 & $p<0,05$ \\
\hline Човниковий біг $4 \times 9$ м, с & 9,6 & 1,05 & 9,4 & 0,82 & $p>0,05$ \\
\hline Рівномірний біг 3000 м, хв & 15,21 & 1,23 & $14,07^{*}$ & 0,98 & $p<0,05$ \\
\hline $\begin{array}{l}\text { Нахил тулуба вперед з положен- } \\
\text { ня сидячи, см }\end{array}$ & 4,47 & 2,56 & 6,8 & 2,87 & $p>0,05$ \\
\hline Стрибок у довжину з місця, см & 221,7 & 22,71 & $249,7^{* *}$ & 10,05 & $p<0,01$ \\
\hline Динамометрія правої кисті, кг & 43,5 & 5,83 & $46,6^{*}$ & 3,22 & $p<0,05$ \\
\hline Динамометрія лівої кисті, кг & 38,7 & 6,34 & 41,4 & 5,06 & $p>0,05$ \\
\hline Ускладнена проба Ромберга, с & 13,1 & 4,25 & $18,9^{*}$ & 1,24 & $p<0,05$ \\
\hline
\end{tabular}

Примітки. * різниця статистично значуща на рівні $p<0,05$; * на рівні $p<0,01$

пи м'язів, які складно задіяти в процесі силових або кардіотренувань.

Отримані результати під час повторного тестування основних рухових якостей виявились вищими за попередні. Значне покращення спостерігається у стрибках у довжину 3 місця, середньогруповий показник збільшився на 28,0 см, що становить $52,1 \%$, та у координаційних зді-
Загалом можна зробити висновок, що за період педагогічного експерименту, який тривав один навчальний рік, у юнаків 18-19 років відбулися позитивні зміни у всіх показниках фізичнної підготовленості. Спостерігається значна варіативність протягом усього періоду занять у показнику гнучкості, а середньогруповий показник у юнаків має незадовільний бал.

Завдяки заняттям функціональним тренінгом переважна більшість $78,6 \%$ - юнаків змогли скласти тести і нормативи щорічного оцінювання фрізичної підготовленості населення України, та отримати позитивні бали.

Висновки. Критеріями оздоровчого та тренувального ефректу занять фуункціональним тренінгом слугували показники фрізичного стану юнаків 18-19 років. Протягом педагогічного експерименту було виявлено їх позитивну динаміку. Відбулося зменшення показника ЧСС у стані спокою $(p<0,05)$, покращення функціональної здатності серцевого м'яза, покращення резервних можливостей серцево-судинної та дихальної систем, що проявилось у знижені абсолютних значень індексу Руфф'є та Робінсона ( $p<0,05 ; p<0,01)$, і збільшені показників у дихальних пробах Генчі і Штанге $(p<0,05 ; p<0,01)$. Функціональний тренінг сприяв збалансованому розвитку усіх складових фізичної підготовленості, зокрема швидкості, сили, витривалості, координації, спритності і гнучкості.

Конфлікт інтересів. Автори заявляють, що відсутній будь-який конфрлікт інтересів.

\section{ЛІТЕРАТУРА}

1. Андрєєва 0. Аналіз сучасних концептуальних моделей фрізичної рекреації. Теорія і методика фіз. виховання і спорту. 2012;1:42-46.

2. Андрєєва О. Концептуальні та прикладні аспекти технологізації проектувальної діяльності в сфері фрізичної рекреації. Теорія і методика фріз. виховання і спорту. 2013;1:35-40.

3. Андрєєва ОВ. Фізична рекреація різних груп населення. Київ Поліграфсервіс, 2014. $280 \mathrm{c}$.

4. Базилевич НО, Тонконог ОС. Особливості використання нового виду спорту «Crossfit» у самостійній фізкультурно-оздоровчій роботі студентів. Гуманітарний Вісник ДВНЗ «Переяслав-Хм. ДПУ імені Григорія Сковороди». Спецвипуск. 2016;136-142.

5. Благій ОЛ, Захаріна Є0. Організаційнопедагогічні умови формування мотивації студентів до рухової активності в процесі 
фізичного виховання. Теорія і методика фізичного виховання і спорту. 2009;4:92-96.

6. Дутчак М. Парадигма оздоровчої рухової активності: теоретичне обгрунтування і практичне застосування. Теорія і методика фіз. виховання і спорту. 2015;2:44-52.

7. Кормильцев В, Лазарева Е. Применение функционального тренинга в физической реабилитации лиц с вертеброгенной патологией Фізичне виховання, спорт і культура здоров'я у сучасному суспільстві. 2012;(3):291-294.

8. Неханевич ОБ. Ознаки перенапружен ня серцево-судинної системи за показниками діастолічної функції лівого шлуночка серця спортсменів під час фрізичних навантажень різної потужності. Вісник проблем біології і медицини. 2015;(2):187-192.

9. Попов СВ, Бокова СИ, Бугаенко ВА, Рома нова ТА. Особенности функционального статуса сердечно-сосудистой системы у подростков по данным допплерограсрии. Журнал клінічних та експериментальних медичних досліджень. 2013;(4):432-436

10. Церковна О, Барибіна Л, Філенко Л, Пасько В, Полторацька Г, Басенко О. Анапіз структури захворюваності студентів різ нопрофільних вишів для пошуку шляхів оптимізації фрізичного виховання. Спортивна наука України. 2017;(2):47-56.

11. Церковная $\mathrm{E}$, Осипов В, Филенко Л, Пасько В. Динамика изменений структуры и уровня заболеваемости студентов техническо го вуза. Слобожанський науково-спортивний вісник. 2017;(58):102-106. DOI: 10.15391/snsv. 2017-2.018

12. Цись ДІ, Цись НО. Теоретичні аспекти підвищення фізичної підготовленості студентів вищих навчальних закладів. Перспективные достижения современных ученых: образование и воспитание, физическое воспитание и спорт монография. Одесса, 2017;51-57.

13. Ярмак ОМ. Аналіз захворюваност студентської молоді Білоцерківського націо нального аграрного університету протягом 2014-2015 н.р. Вісник Східноєвропейського національного університету імені Лесі Українки, серія: Фізичне виховання, спорт і культура здоров'я у сучасному суспільстві. 2015;(25):56 59.

14. Kokorev DA, Veprikov DV, Vetericyn OV, Bodrov IM. The method of using a functional al laround (Crossfit) in the process of students physical education. Theory and Practice of Physical Culture, 2016:9:16-18

15. Yarmak O, Kyselytsia O, Moseychuk $Y$, Dotsyuk L, Palichuk Y, Galan Y. Comparative analysis of parameters of the physical condition of 17-19-years-old male youths with different motion activity level. Journal of Physical Education and Sport. 2018;18(1):276-281. DOI: 10.7752/ jpes.2018.01037

\section{LITERATURE}

1. Andreieva 0 . Analysis of modern conceptual models of physical recreation. Teoriia i metodyka fizvykhovannia i sportu. 2012;1:42-46.

2. Andreieva 0. Conceptual and applied aspects of projective activity technologization in physical recreation. Teoriia i metodyka fizvyk hovannia i sportu. 2013;1:35-40.

3. Andreieva OV. Physical recreation of different population groups. Kyiv Poligrafservis, 2014 $280 \mathrm{p}$.

4. Bazylevych NO, Tonkonoh OS. Features of using "Crossfit" new sports event in independent physical culture and health-related activity of students. Humanitarnyi visnyk DVNZ "PereiaslavKhm. SPU imeni H. Skovorody". Special issue. 2016;136-142.

5. Blahii 0, Zakharina I. Organizational and pedagogical conditions for student motivation for mation for motor activity in the process of physical education. Teoriia i metodyka fizvykhovannia sportu. 2009;4:92-96

6. Dutchak M. Paradigm of health-related motor activity: theoretical substantiation and practica usage. Teoriia i metodyka fizvykhovannia i sportu. 2015;2:44-52.

7. Kormiltsev V, Lazareva E. Functional training use in physical rehabilitation of patients with vertebrogenic pathology. Fizvykhovannia sport i kultura zdorovia u suchasnomu suspilstvi. 2012;(3):291-294.

8. Nekhanevich OB. Signs of cardiovascular system overstrain according to indices of left ventricle diastolic function of athletes during physical loads of different power. Visnyk problem biolohii medytsyny. 2015;(2):187-192.
9. Popov SV, Bokova SI, Buhaienko VA, Romanova TA. Features of cardiovascular system functional status in adolescents according to dopplerography. Zhurnal klinichnykh ta eksperymentalnykh doslidzhen. 2013;(4):432-436

10. Tserkovna O, Barybina L, Filenko L, Pasko V, Poltoratska H, Basenko 0._Analysis of the morbidity structure of students of various universities to find ways to optimize physical education. Sportyvna nauka Ukrainy. 2017;(2):47-56

11. Tserkovnaya $\mathrm{E}$ Osipov V, Filenko L, Pasko V. Dynamics of changes in morbidity structure and leve; in students of technical education institutions. Slobozhanskyi naukovo-sport. visnyk. 2017:(58):102-106. DOI: 10.15391/snsv.2017-2.018

12. Tsys D, Tsys N. Theoretical aspects of advancing the physical preparation of students in their primary positions. Promising achievements of modern scientists: education and upbringing, physical upbringing and sport: monograph. Odessa, 2017;51-57.

13. Yarmak OM. Analysis of student youth morbidity of Bila Tserkva national university during 2014-2015. Visnyk Skhidnoievropeyskoho universytetu im. Lesi Ukrainky. 2015;(25):56-59.

14. Kokorev DA, Veprikov DV, Vetericyn OV, Bodrov IM. The method of using a functional allaround (Crossfit) in the process of students' physical education. Theory and Practice of Physical Culture, 2016;9:16-18.

15. Yarmak 0 , Kyselytsia 0 , Moseychuk $Y$, Dotsyuk L, Palichuk Y, Galan Y. Comparative analysis of parameters of the physical condition of 17-19-years-old male youths with different motion activity level. Journal of Physical Education and Sport. 2018;18(1):276-281. DOI: 10.7752/ jpes.2018.01037

Надійшла 11.01.2021

\section{ІНФОРМАЦІЯ ПРО АВТОРІВ}

Петрачков Олександр Валерійович orcid.org/0000-0002-6684-1641, apetrachkov77@ukr.net Національний університет оборони України імені Івана Черняховського 03049, Київ, Повітрофлотський проспект, 28

Ярмак Олена Миколаївна orcid id 0000-0002-6580-6123, yarmak_en@ukr.net

Білоцерківський національний аграрний університет

09117, Київська область, Біла Церква, Соборна пл., 8/1

\section{INFORMATION ABOUT THE AUTHORS}

Petrachkov Oleksandr orcid.org/0000-0002-6684-1641, apetrachkov77@ukr.net

The National Defense University of Ukraine named after Ivan Cherniakhovskyi 03049, Kyiv, Povitroflotsky Ave, 28

Yarmak Olena orcid id 0000-0002-6580-6123, yarmak_en@ukr.net

Bila Tserkva National Agrarian University

09117, Kyiv region, Bila Tserkva, Soborna sq. 8/1 